\title{
Ambulatory Blood Pressure Monitoring: An Invaluable Tool Comes of Age for Patients with Chronic Kidney Disease?
}

\author{
Pantelis A. Sarafidis Adam Rumjon lain C. Macdougall \\ Academic Department of Renal Medicine, King's College Hospital, London, UK
}

Hypertension is the most common chronic disease in the Western world, with a documented prevalence of $25-$ $30 \%$ of adults in developed societies [1], and a major risk factor for cardiovascular events; thus, it is no wonder why it is considered the most important attributable cause of death worldwide [2]. Chronic kidney disease (CKD), on the other hand, is another major public health issue; it is also a potent risk factor for cardiovascular morbidity and mortality, and it has a prevalence of around $10 \%$ of adults, with incident end-stage renal disease (ESRD) increasing much faster than expected from CKD growth [3]. Elevated blood pressure (BP) is an established cause, but can also be a consequence of kidney injury [4], and hypertension prevalence rates are $>90 \%$ in individuals with advanced CKD [5]. Thus, all previous major guidelines in the field have put increased emphasis on the quick diagnosis and aggressive control of BP in CKD patients $[2,4$, 6, 7].

Despite substantial efforts from health authorities and effective treatment options being available for decades, $\mathrm{BP}$ control rates in the general population remain low in many countries [8] and they are even worse in CKD patients [5]. Of note, reduced hypertension awareness leading to inadequate treatment is proposed as a major factor contributing to poor control, both in the general population and individuals with CKD $[5,8]$, highlighting the need for proper diagnosis of elevated BP levels. Tra- ditionally, hypertension diagnosis is based on clinic BP measurements during three separate visits, while other available strategies, such as home measurements and ambulatory BP monitoring (ABPM), the 'gold standard' of diagnosis, are reserved for uncertain cases, including suspicion of 'white-coat' and 'masked' hypertension [2].

A very important recent study [9] compared the costeffectiveness of the three aforementioned strategies for diagnosis of essential hypertension. The authors performed a Markov-model analysis on a hypothetical primary-care population older than 40 years with a screening $\mathrm{BP}$ reading $>140 / 90 \mathrm{~mm} \mathrm{Hg}$. They concluded that ABPM was clearly the most cost-effective strategy, producing cost-savings for all gender- and age-stratified groups studied and gains in quality-adjusted life years (QALYs) for older subjects. Clearly, the greater cost-effectiveness of ABPM was due to higher diagnostic accuracy in detecting hypertension [10], leading to effective treatment and associated reductions in cardiovascular events in more hypertensive individuals, and less unnecessary treatment of people without hypertension. Several methodological strengths support the validity of this study's conclusions [9]. The model was run separately for ten gender- and age-stratified groups; the study time horizon was particularly long and a reasonable annual discount rate was applied; periodic rechecking of $\mathrm{BP}$ was incorporated to allow for the possibility that peo-

\section{KARGER}

Fax +4161306 1234 E-Mail karger@karger.ch www.karger.com

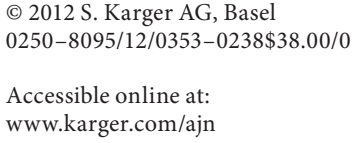

Pantelis A. Sarafidis, $\mathrm{MD}, \mathrm{MSc}, \mathrm{PhD}$

Academic Department of Renal Medicine

King's College Hospital

Denmark Hill, London SE5 9RS (UK)

Tel. +44207848 0431, E-Mail psarafidis11@yahoo.gr 
ple not hypertensive at baseline could become hypertensive over time; cost inputs were based on published data and covered all potential sources of cost. Furthermore, gender- and age-specific risks of cardiovascular events were properly calculated, and clinical inputs on sensitivity/specificity of studied diagnostic options and relevant risk reductions with antihypertensive treatment were based on recent, high-quality, meta-analyses $[10,11]$. Finally, the issue of uncertainty was extensively investigated in deterministic and further probabilistic sensitivity analyses, supporting the robustness of the results with limited exceptions.

As in all cost-effectiveness analyses, however, a number of unavoidable assumptions relating to potential limitations were also present [9]. The model considered treatment of hypertension as a dichotomous decision, but relevant recommendations suggest this to be based on an integrated approach to total cardiovascular risk [2]. The authors assumed that people with falsely diagnosed hypertension gain no benefit or harm from unnecessary treatment (as there were no data available to quantify relevant effects). Observational evidence suggests that the risks associated with $\mathrm{BP}$ are continuous down to $115 \mathrm{~mm}$ $\mathrm{Hg}$ systolic, but clinical trial data on treatment benefits for patients below current thresholds are controversial [12]. However, disease-labeling and unnecessary treatment almost certainly signifies an (even small) risk of side effects and QALY reductions. Treatment costs were based on most commonly used (and often much cheaper) generic drugs; in practice more expensive drugs are often also prescribed. The analysis only used cost and QALY inputs for first non-fatal cardiovascular events; repeat events were not modeled. Furthermore, the clinical endpoints used referred only to cardiovascular events and excluded other sources of morbidity associated with hypertension, most importantly CKD. Lastly, as in most relevant analyses, cost data were derived from a single country environment, rendering the generalizability of the study findings to other healthcare settings unknown. It is interesting, however, that a hypothetical correction of most of these limitations would rather result in higher lifetime costs associated with hypertension, indicating that cost-savings from correct diagnosis with ABPM could in reality be greater. In other words, most of the above assumptions lead to more conservative estimates and, if absent, would further strengthen the case for ABPM; thus, quite paradoxically, these limitations rather add to the study conclusions.

Without doubt, this study has direct clinical implications for the general population. Although the advan- tages of ABPM are widely accepted [2], its everyday use is currently rather restricted worldwide in tertiary hypertension centers, with relevant infrastructure and experience; in contrast, this study highlights the need for a major shift in general practice, with ABPM being used in all patients with an elevated clinic reading [9]. Furthermore, the implications of the usefulness and related cost-effectiveness of detecting hypertension with ABPM may be even more important for patients with CKD, for several reasons. Due the high prevalence of hypertension in patients with CKD [4-6], it is perhaps by far the most important risk factor for both kidney and cardiovascular disease progression in such individuals; thus, an accurate diagnosis of the exact $\mathrm{BP}$ levels may be much more critical in patients with CKD than in individuals without other co-morbidities. In addition, recent evidence suggests that the BP target to achieve renoprotection may be different within non-diabetic patients with $\mathrm{CKD}$, with $\mathrm{BP}$ reduction to $<130 / 80 \mathrm{~mm} \mathrm{Hg}$ being beneficial for proteinuric CKD patients, but not necessary for those without proteinuria [13]. Given the inherent inaccuracy of clinic BP measurements [10], it may be difficult for the practicing nephrologist to delineate the exact $\mathrm{BP}$ in patients with kidney injury presenting with 'borderline' BP levels; this further exemplifies the utility of ABPM to secure accurate diagnosis and guide treatment decisions in patients with CKD. Finally, an old problem of the practicing nephrologists is that of adequate diagnosis of hypertension in patients with ESRD undergoing hemodialysis; pre- or post-dialysis BP levels are greatly confounded by numerous issues, including fluid status before, as well as magnitude and speed of fluid removal during a dialysis session, and are known to poorly reflect the true BP during the interdialytic period [14]. As evident by recent data, the use of ABPM over $48 \mathrm{~h}$ (i.e. covering both the dialysis and interdialytic period) may be the best way to assess true BP levels and properly diagnose hypertension in these patients [15], thus providing another reason for increased ABPM use in nephrology units.

In addition to the above issue of adequately diagnosing hypertension, ABPM has long been known to have several other advantages, including superior predictive value for both intermediate outcomes of target-organ damage and cardiovascular morbidity and mortality. This is largely attributed to ABPM providing information on factors such as non-dipping status and BP variability, which have been shown to predict target-organ damage, but cannot be captured with clinic BP readings [16]. Current evidence derived from numerous observational 
studies in a wide range of populations (such as patients with essential hypertension, type 2 diabetes mellitus, and the elderly) clearly suggests the higher prognostic value of ABPM also for renal outcomes, including progression of albuminuria, decline of estimated glomerular function (eGFR), and incident ESRD, as recently summarized elsewhere [17]. Moreover, with regard to patients with CKD and ESRD, observations for increased frequency of nondipping status and altered BP variability associated with target-organ injury $[18,19]$ have progressively evolved to several pieces of evidence, suggesting superiority of ABPM in predicting cardiovascular events and mortality $[20,21]$. A recent study on this issue followed 436 patients with CKD (mean eGFR $43 \mathrm{ml} / \mathrm{min} / \mathrm{m}^{2}$ ) for a median of 4.2 years with end-points time to renal death (ESRD or death) and time to fatal and non-fatal cardiovascular events; the results showed a clear stratification of risk with quintiles of daytime and, particularly, nighttime BP levels recorded with ABPM, whereas office BP did not have any prognostic associations [22].

Finally, another major advantage of ABPM is to aid towards improved control of hypertension, which, as discussed above, remains very poor in the general population and even more so in patients with CKD $[5,8]$. The notion of inadequate control is confounded by a high prevalence of the 'white-coat' effect within patients with essential hypertension receiving treatment [23]; a similar problem is also suggested in hypertensive individuals with CKD [20]. Due to the above, use of ABPM to identify the exact levels of BP is currently proposed as a basic step in the investigation of people with poorly controlled or 'resistant' hypertension, many of which also have CKD [23]. Further, due to the aforementioned association of nighttime $\mathrm{BP}$ with increased risk in patients with $\mathrm{CKD}$, previous studies have used ABPM to assess the effect of nocturnal dosing of medications on BP [24]. The most recent of them randomized 661 hypertensive patients with various stages of CKD to take all prescribed hypertension medications upon awakening or at least one at bedtime for a median of 5.4 years; the latter group had lower sleep-time BP, better control rate, and an adjusted risk for cardiovascular events that was approximately one-third of that of patients who took all medications upon awakening [25].

Overall, in patients with CKD the use ABPM may confer a number of important benefits, which start from accurate risk stratification and may extend to proper diagnosis of BP levels and assessment of 24-hour BP control. Following recent important evidence on the cost-effectiveness of ABPM in detecting hypertension in the general practice, it would be interesting to see future studies incorporating data on the prognostic value of ABPM in CKD patients to explore the accuracy and the cost-effectiveness of ABPM for assessing hypertension diagnosis and treatment adequacy in CKD.

\section{References}

-1 Wolf-Maier K, Cooper RS, Banegas JR, Giampaoli S, Hense HW, Joffres M, Kastarinen M, Poulter N, Primatesta P, Rodriguez-Artalejo F, Stegmayr B, Thamm M, Tuomilehto J, Vanuzzo D, Vescio F: Hypertension prevalence and blood pressure levels in six European countries, Canada, and the United States. JAMA 2003;289:2363-2369.

-2 Mancia G, De BG, Dominiczak A, Cifkova R, Fagard R, Germano G, Grassi G, Heagerty AM, Kjeldsen SE, Laurent S, Narkiewicz K, Ruilope L, Rynkiewicz A, Schmieder RE, Boudier HA, Zanchetti A, Vahanian A, Camm J, De CR, Dean V, Dickstein K, Filippatos G, Funck-Brentano C, Hellemans I, Kristensen SD, McGregor K, Sechtem U, Silber S, Tendera M, Widimsky P, Zamorano JL, Erdine S, Kiowski W, Gabiti-Rosei E, Ambrosioni E, Lindholm LH, Viigimaa M, Adamopoulos S, Gabiti-Rosei E, Ambrosioni E, Bertomeu V, Clement D, Erdine S, Farsang C, Gaita D, Lip G, Mallion JM, Manolis AJ, Nilsson PM, O’Brien E, Ponikowski P, Redon
J, Ruschitzka F, Tamargo J, van ZP, Waeber B, Williams B: 2007 Guidelines for the Management of Arterial Hypertension: the Task Force for the Management of Arterial Hypertension of the European Society of Hypertension (ESH) and of the European Society of Cardiology (ESC). J Hypertens 2007; 25:1105-1187.

-3 Hsu CY, Vittinghoff E, Lin F, Shlipak MG: The incidence of end-stage renal disease is increasing faster than the prevalence of chronic renal insufficiency. Ann Intern Med 2004;141:95-101.

4 Bakris GL, Ritz E: The message for World Kidney Day 2009: hypertension and kidney disease: a marriage that should be prevented. Am J Nephrol 2009;30:95-98.

$\checkmark 5$ Sarafidis PA, Li S, Chen SC, Collins AJ, Brown WW, Klag MJ, Bakris GL: Hypertension awareness, treatment, and control in chronic kidney disease. Am J Med 2008;121:332-340.

-6 K/DOQI clinical practice guidelines on hypertension and antihypertensive agents in chronic kidney disease. Am J Kidney Dis 2004;43:1-290.

7 Chobanian AV, Bakris GL, Black HR, Cushman WC, Green LA, Izzo JL Jr, Jones DW, Materson BJ, Oparil S, Wright JT Jr, Roccella EJ: The Seventh Report of the Joint National Committee on Prevention, Detection, Evaluation, and Treatment of High Blood Pressure: the JNC 7 Report. JAMA 2003;289: 2560-2572.

$\checkmark 8$ Wolf-Maier K, Cooper RS, Kramer H, Banegas JR, Giampaoli S, Joffres MR, Poulter N, Primatesta P, Stegmayr B, Thamm M: Hypertension treatment and control in five European countries, Canada, and the United States. Hypertension 2004;43:10-17.

$\checkmark 9$ Lovibond K, Jowett S, Barton P, Caulfield M, Heneghan C, Hobbs FD, Hodgkinson J, Mant J, Martin U, Williams B, Wonderling D, McManus RJ: Cost-effectiveness of options for the diagnosis of high blood pressure in primary care: a modelling study. Lancet 2011;378:1219-1230. 
10 Hodgkinson J, Mant J, Martin U, Guo B, Hobbs FD, Deeks JJ, Heneghan C, Roberts N, McManus RJ: Relative effectiveness of clinic and home blood pressure monitoring compared with ambulatory blood pressure monitoring in diagnosis of hypertension: systematic review. BMJ 2011;342:d3621.

11 Law MR, Morris JK, Wald NJ: Use of blood pressure lowering drugs in the prevention of cardiovascular disease: meta-analysis of 147 randomised trials in the context of expectations from prospective epidemiological studies. BMJ 2009;338:b1665.

12 Mancia G, Laurent S, Agabiti-Rosei E, Ambrosioni E, Burnier M, Caulfield MJ, Cifkova R, Clement D, Coca A, Dominiczak A, Erdine S, Fagard R, Farsang C, Grassi G, Haller $\mathrm{H}$, Heagerty A, Kjeldsen SE, Kiowski W, Mallion JM, Manolis A, Narkiewicz K, Nilsson P, Olsen MH, Rahn KH, Redon J, Rodicio J, Ruilope L, Schmieder RE, Struijker-Boudier HA, van Zwieten PA, Viigimaa M, Zanchetti A: Reappraisal of European guidelines on hypertension management: a European Society of Hypertension Task Force document. J Hypertens 2009;27:2121-2158.
3 Appel LJ, Wright JT Jr, Greene T, Agodoa LY, Astor BC, Bakris GL, Cleveland $\mathrm{WH}$ Charleston J, Contreras G, Faulkner ML, Gabbai FB, Gassman JJ, Hebert LA, Jamerson KA, Kopple JD, Kusek JW, Lash JP, Lea JP, Lewis JB, Lipkowitz MS, Massry SG, Miller ER, Norris K, Phillips RA, Pogue VA, Randall OS, Rostand SG, Smogorzewski MJ, Toto RD, Wang X: Intensive blood-pressure control in hypertensive chronic kidney disease. N Engl J Med 2010;363:918-929.

14 Agarwal R, Peixoto AJ, Santos SF, Zoccali C: Pre- and postdialysis blood pressures are imprecise estimates of interdialytic ambulatory blood pressure. Clin J Am Soc Nephrol 2006;1:389-398.

15 Agarwal R: Epidemiology of interdialytic ambulatory hypertension and the role of volume excess. Am J Nephrol 2011;34:381-390.

16 Mancia G, Parati G: Guiding antihypertensive treatment decisions using ambulatory blood pressure monitoring. Curr Hypertens Rep 2006;8:330-337.

17 Tsioufis C, Andrikou I, Thomopoulos C, Petras D, Manolis A, Stefanadis C: Comparative prognostic role of nighttime blood pressure and nondipping profile on renal outcomes. Am J Nephrol 2011;33:277-288.

18 Szelestei T, Kovacs T, Barta J, Nagy J: Circadian blood pressure changes and cardiac abnormalities in IgA nephropathy. Am J Nephrol 1999;19:546-551.

-19 Agarwal R, Kariyanna SS, Light RP: Circadian blood pressure classification scheme and the health of patients with chronic kidney disease. Am J Nephrol 2009;30:536-546.
20 Agarwal R: Home and ambulatory blood pressure monitoring in chronic kidney disease. Curr Opin Nephrol Hypertens 2009; 18 : 507-512.

21 Agarwal R: Blood pressure and mortality among hemodialysis patients. Hypertension 2010;55:762-768.

-22 Minutolo R, Agarwal R, Borrelli S, Chiodini P, Bellizzi V, Nappi F, Cianciaruso B, Zamboli P, Conte G, Gabbai FB, De Nicola L: Prognostic role of ambulatory blood pressure measurement in patients with nondialysis chronic kidney disease. Arch Intern Med 2011;171:1090-1098.

23 Sarafidis PA, Bakris GL: Resistant hypertension: an overview of evaluation and treatment. J Am Coll Cardiol 2008;52:1749-1757.

24 Minutolo R, Gabbai FB, Borrelli S, Scigliano R, Trucillo P, Baldanza D, Laurino S, Mascia S, Conte G, De Nicola L: Changing the timing of antihypertensive therapy to reduce nocturnal blood pressure in CKD: an 8-week uncontrolled trial. Am J Kidney Dis 2007;50: 908-917.

25 Hermida RC, Ayala DE, Mojon A, Fernandez JR: Decreasing sleep-time blood pressure determined by ambulatory monitoring reduces cardiovascular risk. J Am Coll Cardiol 2011; 58:1165-1173. 